Bull. Chem. Soc. Ethiop. 2018, 32(1), 1-12.

ISSN 1011-3924

(c) 2018 Chemical Society of Ethiopia and The Authors

Printed in Ethiopia

DOI: https://dx.doi.org/10.4314/bcse.v32i1.1

\title{
CORRELATION OF ANTIOXIDANT ACTIVITY OF DRIED BERRY INFUSIONS WITH THE POLYPHENOLS AND SELECTED MICROELEMENTS CONTENTS
}

\author{
Mihaela Mirela Bratu ${ }^{1}$, Semaghiul Birghila ${ }^{2 *}$, Antoanela Popescu ${ }^{1}$, Bogdan Stefan Negreanu- \\ Pirjol $^{1}$ and Ticuta Negreanu-Pirjol ${ }^{1}$ \\ ${ }^{1}$ Departmment of Pharmaceutical Sciences II, Ovidius University of Constantza, Aleea \\ University Avenue, Campus 1, 900470, Constantza, Romania \\ ${ }^{2}$ Departmment of Chemistry and Chemical Engineering, Ovidius University of Constantza, 124 \\ Mamaia, 900527, Constantza, Romania
}

(Received January 21, 2017; Revised March 23, 2018; Accepted March 24, 2018)

\begin{abstract}
Antioxidant activity was measured by ferric reducing ability of plasma (FRAP) assay in seven types of infusions prepared from commercial dried berry fruit products: Rosa canina, Vaccinium vitis-idaea, Hiphophae rhamnoides, Hibiscus sabdariffa and three fruit mixtures. Total polyphenols (TP), total anthocyanins and the polyphenolic compounds were determined by HPLC equipped with diode array detector. To estimate the amount of elements released from fruits into the water extracts, levels of $\mathrm{Fe}, \mathrm{Mn}, \mathrm{Zn}$ and $\mathrm{Cu}$ in dried samples and in infusions were determined by flame atomic absorption spectrometry. The correlation between polyphenols content and the antioxidant activities and the microelements in the infusions and the antioxidant activities were estimated using the Pearson's correlation test. The results showed a high, positive and significant correlation $(\mathrm{r}=$ 0.9465 ) between the FRAP values and TP content, meaning that the concentration of phenolic compounds may be a good indicator of the reducing capacity in the infusions. Correlations varied (positive, negative and weak) between antioxidant and mineral extractability of berry infusions. Among the polyphenolic compounds, gallic acid contributed particularly to the antioxidant capacity of the studied samples $(r=0.563)$. The correlation of antioxidants, total polyphenols with mineral extractability showed the influence of antioxidant compound on mineral bioavailability.
\end{abstract}

KEY WORDS: Mixed berry infusion, Antioxidant activity, Phenolic compounds, Microelements

\section{INTRODUCTION}

Berry fruits are an important source of phytonutrients with considerable health benefits for human. Due to their high content in vitamins, phenolic compounds and minerals, they are widely recommended in the healthy human diet $[1,2]$. Measurements of antioxidant activity using different methods in berry fruits lead to the conclusion that they have considerable high antioxidant capacity $[3,4]$. It is considered that many of the health benefits associated with berry fruits dietary intake are linked to their high polyphenols content. As a consequence, a growing number of scientific reports attempting to clearly address this link are now available [5, 6]. A mixture of berry/wild fruits is used in winter time, to prepare various beverages considered as having both nutritional and therapeutic benefits. The traditional tisanes prepared by infusing the dried berry/wild fruits are nowadays rediscovered and plenty of commercial products containing dried berry/wild fruits promote their antioxidant effects against degenerative chronic diseases such as cancer, diabetes and atherosclerosis [1].

Because it is relatively easy to produce food supplements containing dried berries, many companies produce such products. Due to their atractive flavours and special taste, these berry fruit teas are increasingly appreciated by the customers and are becoming popular beverages [7]. The most widely used wild fruits in the commercial dried fruit mixtures called berry fruit teas are: rose hip (Rosa spp fruits), sea buckthorn berries (Hiphophae rhamnoides fruits) and

*Corresponding author. E-mail: semabirghila@yahoo.com

This work is licensed under the Creative Commons Attribution 4.0 International License 
lingonberries (Vaccinium vitis-idaea fruits). Also, in all those products added are Hibiscus sabdariffa calyces due to their high anthocyanins and organic acids content, which render to the infusion a purple red color as well as a sour fruity taste.

There are some studies regarding the amount of phenolic antioxidants in the berry fruit teas $[8,9]$. However, there are not enough studies which determine the chemical composition mainly in bioactive molecules and selected microelements and to demonstrate the antioxidant potential of the infusions prepared and ingested by people [10]. Studies regarding the amount of mineral elements together with phenolic compounds and antioxidant activities were performed only in other popular herbal teas [11], but not in the berry fruits infusions.

The aims of the present work was to asses the health benefits of the berry fruit teas infusions by: (i) quantifying the phenolic compounds; (ii) measuring the antioxidant activities; (iii) evaluating the amount of elements released from fruits into the water extracts. Correlations between different groups of phenolic compounds content and antioxidant activity as well as between some microelements and antioxidant activity could clarify the role of those molecules and ions in the protection against oxidative factors.

\section{MATERIALS AND METHODS}

\section{Chemicals}

All phenolic standards and solvents used in this work were of HPLC - grade (purity > 99\%). Water, methanol, ethanol, and acetonitrile were purchased from Sigma Aldrich (Steinheim, Germany), 2,4,6-tripyridyl-s-triazine (TPTZ) and Folin-Ciocalteu reagents were obtained from Merck (Darmstadt, Germany). The phenolic standard containing gallic acid, 3-methyl gallic acid, caffeic acid, $p$-coumaric acid, ferulic acid, resveratrol, ellagic acid and cinamic acid was purchased from Sigma Aldrich (Steinheim, Germany). Standard solutions of Fe, Mn, $\mathrm{Cu}$ and $\mathrm{Zn}$ were prepared from $1000 \mathrm{mg}$ element $\mathrm{L}^{-1}$ atomic absorption standard solutions (Merck Darmstadt, Germany).

\section{Tea samples and preparation}

Seven commercial berry fruit teas were purchased from local market (Table 1). Prior to analysis, each of the sample was homogenized and ground into fine powder using a laboratory mixer. In order to simulate the ordinary household preparation conditions, tea infusions were prepared according to the instructions provided on the packaging. Tea infusions were prepared by boiling $80 \mathrm{~mL}$ of deionized water and pouring the boiling water over $2 \mathrm{~g}$ of the sample into a standardized Erlenmeyer flask. The tea infusion was stirred with a glass rod to ensure proper wetting, covered and steeped for $10 \mathrm{~min}$ (according to the producer's instructions). Subsequently, the steeped infusion was filtered through of $5 \mu \mathrm{m}$ filter paper into a volumetric flask and diluted with deionized water to $100 \mathrm{~mL}$. For HPLC detection of phenolic compounds in the infusions, the samples were filtered using $0.45 \mu \mathrm{m}$ (Millipore - Sigma) filters before injecting into the columns.

\section{Total anthocyanins determination}

The total anthocyanins $(\mathrm{ACN})$ were determined using the pH-differential method described by Giusti and Wrolstad [12]. Absorbencies were read at $510 \mathrm{~nm}$ for ACN content and $700 \mathrm{~nm}$ for haze correction using an UV-Visible spectrophotometer (Jasco V-630). Concentration of total anthocyanins was calculated as cyanidin-3-glucoside/100 $\mathrm{mL}$ infusion. The difference in absorbance values at $\mathrm{pH} 1.0$ and 4.5 was directly proportional to $\mathrm{ACN}$ concentration. The $\mathrm{pH}$ of infusions was measured potentiomertically with a $\mathrm{pH}$ meter (WTW Inolab Level 1, Wielheim, Germany). 
Table 1. Berry fruit teas.

\begin{tabular}{|l|l|l|}
\hline Sample & Code & Sample description \\
\hline Sample 1 & BT1 & Dried rose hip (Rosa spp fruits) \\
\hline Sample 2 & BT2 & Dried lingonberries (Vaccinium vitis-idaea fruits) \\
\hline Sample 3 & BT3 & Dried sea buckthorn berries (Hiphophae rhamnoides fruits) \\
\hline Sample 4 & BT4 & Hibiscus sabdariffa dried calyces \\
\hline Sample 5 & BT5 & $\begin{array}{l}\text { A product with commercial name "bilberries tea" which, according to the } \\
\text { label contains: min. } 60 \% \text { berry fruits (aronia, black currant, apple, rose hip, } \\
\text { raspberry), Hibiscus calyces and 2\% bilberries }\end{array}$ \\
\hline Sample 6 & BT6 & $\begin{array}{l}\text { A product with commercial name "berry fruits tea" which, according to the } \\
\text { label contains: min. 46\% berry fruits (aronia, black currant, rose hip, } \\
\text { raspberry, bilberry, blueberry), Hibiscus calyces, apples }\end{array}$ \\
\hline Sample 7 & BT7 & $\begin{array}{l}\text { A product with commercial name "Carpathian fruits" which, according to } \\
\text { the label contains a min. 60\% berries mixture (aronia, black currant, apple, } \\
\text { rose hip, bilberry, raspberry, strawberry, wild strawberry, sweet cherry), } \\
\text { Hibiscus calyces. }\end{array}$ \\
\hline
\end{tabular}

\section{Determination of total phenolic content}

The total phenolic content was determined using the Folin-Ciocalteu reagent according to Singleton method [13]. Gallic acid was used as a calibration standard and results were expressed as gallic acid equivalents (mg GAE/100 $\mathrm{mL}$ infusions). For this purpose, an aliquot $(1 \mathrm{~mL})$ of infusion was added to $1 \mathrm{~mL}$ of the Folin-Ciocalteu reagent (diluted 1:1 with distillated water) and then add to $25 \mathrm{~mL}$ with distillated water (solution B). $1 \mathrm{~mL}$ of solution $\mathrm{B}$ was mixed with $20 \%$ sodium carbonate solution till $5 \mathrm{~mL}$ total volume. After $40 \mathrm{~min}$ storage in the dark, at room temperature, the absorbance was measured at $725 \mathrm{~nm}$, versus prepared blank, using Jasco V-630 UV-VIS Spectrophotometer (Japan). The correlation equation constructed with gallic acid (1 to $\left.10 \mathrm{mg} \mathrm{L}^{-1}\right)$ was $\mathrm{y}=0.0794 \mathrm{x}-0.0055\left(\mathrm{R}^{2}=0.9991\right)$ and the limit of detection was $3.26 \mathrm{mg} \mathrm{L}^{-1}$.

\section{Determination of phenolic compounds by HPLC}

Chromatograhic analyses of common phenolic compounds were performed on an Agilent 1200 HPLC system, equipped with a diode array detector (DAD), quaternary pump, and an autosampler (Agilent Technologies, Santa Clara, CA, USA), using a reference method (USP 30-NF25, 2007), [14].

Phenolic acids were separated on a Zorbax XDB C18 analytical column $(250 \mathrm{~mm}$ x $4 \mathrm{~mm}$, i.d. $5 \mu \mathrm{m}$ size) maintained at $35^{\circ} \mathrm{C}$. The mobile phase used in the analysis consisted of $0.1 \%$ phosphoric acid in water (solvent A) and acetonitrile (solvent B). The solvent gradient conditions for phenolic compounds in volume ratio were as following: $0-13 \min 10 \% \mathrm{~B}, 13-14$ $\min 22 \% \mathrm{~B}, 14-17 \min 40 \% \mathrm{~B}, 17-17.5 \mathrm{~min} 10 \% \mathrm{~B}$ and $17.5-22 \mathrm{~min} 10 \% \mathrm{~B}$.

The injection volume was $20 \mu \mathrm{L}$ and the flow rate was $1.5 \mathrm{~mL} / \mathrm{min}$ and the chromatogram was recorded at $310 \mathrm{~nm}$. Calibration curves were built for each of the compounds by injecting the standards at six different concentrations. DAD response was linear for all phenolic acids within the calibration range of $0.22-0.50 \mathrm{mg} \mathrm{mL}^{-1}$, with correlation coefficients exceeding 0.9953. The results were expressed as $\mathrm{mg} / 100 \mathrm{~mL}$ infusion. The identification of phenolic compounds was performed by comparison of retention times and diode array spectral characteristics with standards and the quantification was based on the peak area calculation.

\section{Antioxidant capacity}

Ferric reducing antioxidant power (FRAP) assay. The ferric reducing antioxidant power (FRAP) assay was performed according to Benzie et al. [15] method. FRAP reagent was 
prepared by mixing $2.5 \mathrm{~mL} 10 \mathrm{mM}$ TPTZ (2,4,6-tripyridyl-s-triazine) in $40 \mathrm{mM} \mathrm{HCl}$ and 2.5 $\mathrm{mL}$ of $300 \mathrm{mM}$ acetate buffer $(\mathrm{pH}=3.6)$ and $2.5 \mathrm{~mL}$ of $20 \mathrm{mM} \mathrm{FeCl}_{3} \cdot 6 \mathrm{H}_{2} \mathrm{O}$. The FRAP reagent was added to $1 \mathrm{~mL}$ of each extract and the mixture was shaken. Reagent blank was prepared by adding $1 \mathrm{~mL}$ of water instead of fruit tea. Absorbance readings of tea samples and the reagent blank were taken after $4 \mathrm{~min}$, at $593 \mathrm{~nm}$ using an UV-Visible spectrophotometer (Jasco V-630). The antioxidant activity was calculated from calibration curve $(\mathrm{y}=0.6721 \mathrm{x}-0.0086)$ with a range $0.1-1.2 \mathrm{mM} \mathrm{FeSO}_{4} / \mathrm{L}$ and with good linearity $\left(\mathrm{R}^{2}=0.9998\right)$. The results, obtained from triplicate analyses, were expressed in $\mathrm{mM} \mathrm{FeSO}_{4} / \mathrm{L}$ infusion.

\section{Determination of microelements content}

In order to evaluate the amount of microelements released into the water extracts, mineral elements in dried fruits and the infusions were analysed.

Preparation of samples. For the determination of the mineral content in berry fruits, homogenized material (5 g each) was processed by the dry-ashing method $[16,17]$. Powdered samples, with three replicates taken from each material, were accurately weighed and placed each in a porcelain crucible, and few drops of concentrated nitric acid was added to the aid ashing. The dry-ashing process was carried out in a muffle furnace by stepwise increase of the temperature up to $550{ }^{\circ} \mathrm{C}$ and the samples left to ash at this temperature for $6 \mathrm{~h}$. The ash was kept in desiccators and then rinsed with $3 \mathrm{M}$ hydrochloric acid. The ash suspension was filtered into a volumetric flash $(50 \mathrm{~mL})$ through Whatman filter paper and the volume was made up to the mark with hydrochloric acid. For the infusions, the samples were filtered and evaporated to dryness and residue was prepared as above for the dry material.

Preparation of standards and analysis of samples. Working standards of $\mathrm{Fe}, \mathrm{Mn}, \mathrm{Cu}$ and $\mathrm{Zn}$ were prepared by diluting concentrated stock solution of $1000 \mathrm{mg} \mathrm{L}^{-1}$ with $0.25 \mathrm{~mol} \mathrm{~L}^{-1}$ nitric acid. Calibration curves were obtained by plotting absorbencies of working standards, determined in the same experimental conditions. Measurements of all of the above mentioned elements were determined in triplicates using a high resolution atomic absorption spectrometer ContrAA 700 (Analytik Jena AG, Germany) in an air-acetylene flame using a continuum radiation source. All calibration curves had linear correlation coefficients $\left(\mathrm{R}^{2}\right)$ higher than 0.998 , indicating good linearity. Limits of detection (LOD) of each studied element were calculated as three times the standard deviation of ten measurements of independent reagent blank solutions. These values were $0.0086,0.0008,0.023$ and $0.072 \mathrm{mg} \mathrm{L}^{-1}$ for $\mathrm{Fe}, \mathrm{Mn}, \mathrm{Cu}$ and $\mathrm{Zn}$, respectively. Recoveries were calculated as differences in metals content in spiked and un-spiked samples relative to the spiked level. The recovery studies, with results between $94 \%$ and $97 \%$, indicated the accuracy of the method.

\section{Statistical analysis}

All results were expressed as mean \pm standard deviation (SD) of triplicate determinations. These evaluations were performed by one way ANOVA and statistical significance by Student's t test was carried to test any significant difference among means. The correlation values were assessed using Pearson correlation. Differences at $\mathrm{p}<0.05$ were considered significant.

\section{RESULTS AND DISCUSSION}

Anthocyanins content

The determination of total anthocyanins $(\mathrm{ACN})$ was performed by $\mathrm{pH}$-differential method and the results are shown in Table 2. 
Table 2. $\mathrm{pH}$, total anthocyanins (ACN), total phenolic (TP) and antioxidant capacity (FRAP) of berry fruit infusions ( \pm standard deviation).

\begin{tabular}{|c|c|c|c|c|}
\hline Sample & $\mathrm{pH}$ & $\begin{array}{c}\text { Total anthocyanin (mg C3GE/100 } \\
\text { mL infusion) }\end{array}$ & $\begin{array}{c}\text { Total phenolic } \\
\text { (mg TA/100 mL infusion) }\end{array}$ & $\begin{array}{c}\text { FRAP assay } \\
\text { (mM FeSO } / \mathrm{L})\end{array}$ \\
\hline BT1 & 3.50 & $0.038 \pm 0.03$ & $89.70 \pm 10.4$ & $19.45 \pm 0.78$ \\
\hline BT2 & 2.62 & $0.200 \pm 0.04$ & $25.46 \pm 0.96$ & $2.31 \pm 0.42$ \\
\hline BT3 & 2.72 & $0.050 \pm 0.01$ & $12.95 \pm 0.84$ & $4.05 \pm 0.25$ \\
\hline BT4 & 2.17 & $7.438 \pm 0.49$ & $25.14 \pm 0.34$ & $5.37 \pm 0.21$ \\
\hline BT5 & 2.32 & $11.94 \pm 0.36$ & $18.72 \pm 2.43$ & $6.97 \pm 0.01$ \\
\hline BT6 & 2.36 & $9.072 \pm 0.06$ & $16.47 \pm 0.03$ & $5.56 \pm 0.26$ \\
\hline BT7 & 2.45 & $9.267 \pm 0.06$ & $18.67 \pm 3.78$ & $5.26 \pm 0.03$ \\
\hline
\end{tabular}

The highest ACN content was determined for mixed fruit infusions, from 9.072 to $11.94 \mathrm{mg}$ $\mathrm{C} 3 \mathrm{GE} / 100 \mathrm{~mL}$. BT1 and BT3 infusions exhibited the lowest anthocyanins content of 0.038 and $0.050 \mathrm{mg} \mathrm{C} 3 \mathrm{GE} / 100 \mathrm{~mL}$. Due to limited information available in the literature on the ACN content in berry teas infusions, we could compare our results only with those obtained by other authors on berry fruits or juices. Comparing ACN content reported for raspberry and blackberry [18], and for raspberry juice [19], the average ACN content in the studied infusions was much lower $(5.43 \mathrm{mg} \mathrm{C} 3 \mathrm{GE} / 100 \mathrm{~mL})$. This is probably due to the fact that fruit juices are produced from fresh fruits, while fruit tea production includes some processing steps that may result in the degradation of anthocyanins. Taking into account the $\mathrm{pH}$ range of the infusions $(2.17-3.50)$, we could reasonably suppose that the anthocyanins are in their flavylium cation form, which contribute to the purple, red and yellow colors of the infusions, are stable and do not turn into other flavonoid compounds.

\section{Total polyphenols and phenolic compositions}

Table 2 presents the total polyphenolic content (TP) and the antioxidant capacity (FRAP) determined for the seven types of berry fruit infusions. The highest TP content was determined for BT1 infusion $(89.69 \mathrm{mg} / 100 \mathrm{~mL}$ GAE) followed by BT2 and BT4 infusions $(25.45$ and $25.13 \mathrm{mg} / 100 \mathrm{~mL}$ GAE), while BT3 sample showed the lowest TP content $(12.00 \mathrm{mg} / 100 \mathrm{~mL}$ GAE). There is a 7.5 fold difference between the highest and the lowest considered infusion in terms of total polyphenolic content.

In comparison with the TP content reported by other authors in mixture fruit infusions (from 323.4 to $1549 \mathrm{mg} / \mathrm{L}$ GAE) [20], or juices $(642.1 \mathrm{mg} / \mathrm{L}$ in raspberry fresh juice [19], the average $\mathrm{TP}$ content of our studied infusions was much lower $(29.59 \mathrm{mg} / 100 \mathrm{~mL} \mathrm{GAE})$. The differences may be related to the cultivars, environmental conditions, fruit maturity and drying procedures, which can lead to the degradation of phenolic compounds.

Seven phenolic acids including two hydroxybenzoic acids (gallic, 3-methyl gallic) and five hydroxycinnamic acids (chlorogenic, cinnamic, caffeic, $p$-coumaric, ellagic) were identified by comparison with the retention times of standards under identical conditions (Table 3). Typical HPLC-DAD chromatograms for standard compounds (a) and phenolic compounds in Vaccinium vitis-idaea infusions (b) are presented in Figure 1. The quantitative data were calculated from their respective calibration curves and amounts of identified phenolic compounds by chromatographic method are summed up in Table 4.

In all the infusions prepared from a single fruit/flower species (samples 1-4) the phenolic compounds detected using HPLC were lower than literature reported for fresh fruits [21-24].

Generally, the amount of various polyphenolic compounds detected in the commercial mixtures was lower than in the infusions prepared from single plant product (samples 1-4). The fact is sustained also by the total polyphenolic content (Table 2) which shows that samples 5-7 contains lower amounts of polyphenolic compounds than the infusions prepared from rose hip 
and Hibiscus. Even those infusions contain less polyphenols, their antioxidant activities were remarkable (Table 3), probably due to other undetected compounds or to the synergic effect of mixture compounds.

Table 3. HPLC determination of individual phenolics in studied infusions. Values are expressed as means in $\mathrm{mg} / 100 \mathrm{~mL} \pm \mathrm{SD}(\mathrm{n}=3)$.

\begin{tabular}{|c|c|c|c|c|c|c|c|}
\hline Tea & Gallic acid & $\begin{array}{c}\text { 3-Methyl } \\
\text { gallic acid }\end{array}$ & $\begin{array}{c}\text { Chlorogenic } \\
\text { acid }\end{array}$ & Caffeic acid & $\begin{array}{c}p \text {-coumaric } \\
\text { acid }\end{array}$ & Ellagic acid & $\begin{array}{c}\text { Cinnamic } \\
\text { acid }\end{array}$ \\
\hline 1 & $4.052 \pm 0.015$ & $0.017 \pm 0.016$ & - & $0.117 \pm 0.002$ & - & - & - \\
\hline 2 & $1.772 \pm 0.023$ & $0.017 \pm 0.017$ & $0.217 \pm 0.003$ & $0.038 \pm 0.003$ & - & $0.583 \pm 0.015$ & $0.516 \pm 0.009$ \\
\hline 3 & $1.766 \pm 0.017$ & $0.012 \pm 0.012$ & $0.132 \pm 0.003$ & - & - & - & - \\
\hline 4 & $4.577 \pm 161$ & - & $1.730 \pm 0.006$ & - & $0.132 \pm 0.001$ & - & - \\
\hline 5 & $1.170 \pm 0.074$ & - & $1.565 \pm 0.006$ & - & - & - & - \\
\hline 6 & $1.029 \pm 0.036$ & - & $1.423 \pm 0.009$ & $0.016 \pm 0.002$ & - & - & - \\
\hline 7 & - & - & $1.324 \pm 0.003$ & $0.033 \pm 0.001$ & - & - & - \\
\hline
\end{tabular}

Tabel 4. Retention time of phenolic compounds standard.

\begin{tabular}{|l|c|}
\hline Compound & Retention time (min) \pm SD \\
\hline Gallic acid & $0.990 \pm 0,025$ \\
\hline 3-Methyl gallic acid & $2.606 \pm 0,008$ \\
\hline Chlorogenic acid & $3.501 \pm 0,015$ \\
\hline Caffeic acid & $4.598 \pm 0,036$ \\
\hline Vanillin & $6.919 \pm 0,051$ \\
\hline$p$-Coumaric acid & $7.187 \pm 0,019$ \\
\hline Ferulic acid & $8.565 \pm 0,058$ \\
\hline$E$-Resveratrol & $14.467 \pm 0,017$ \\
\hline Ellagic acid & $15.30 \pm 0,027$ \\
\hline Z-Resveratrol & $15.75 \pm 0,058$ \\
\hline Cinamic acid & $15.867 \pm 0,007$ \\
\hline
\end{tabular}

\section{Antioxidant activity}

In addition to anthocyanins, other compounds (flavonoids, phenolic acids, vitamins) can contribute to the protective effect against damage of cells. Since the antioxidant capacity of individual dietary compound cannot always be evaluated, the determination of total capacity allows a more realist evaluation of the potential protective effect of a food.

Several methods have been developed to evaluate the total antioxidant capacity of fruits and vegetables. One of this is FRAP assay, which is a simple, convenient and reproducible method that is now widely employed in the antioxidant studies of food samples, plant extracts and beverages [25]. The antioxidant capacity of studied infusions varied considerably $(\mathrm{p}<0.05)$ and range from 2.31 to $19.45 \mathrm{mM} \mathrm{FeSO}_{4} / \mathrm{L}$ (Table 2). The order of FRAP values was as follows: Rosa canina dried fruits (BT1) > mixtures of dried berries (BT5, BT6, BT7) > Hibiscus sabdariffa dried calyces $(\mathrm{BT} 4)>$ Hiphophae rhamnoides fruits $(\mathrm{BT} 3)>$ Vaccinium vitis-idaea fruits (BT2).

These results indicate that the antioxidants present in the rose hip infusion (BT1) are in the highest amount, which is in agreement with the total polyphenolic compounds content found in this type of infusion. Buricova et al. [26] determined the antioxidant activity of 17 Czech medicinal plants. The authors found a good antioxidant activity in the watery and ethanol extracts of blueberry fruits by DPPH method (34.2 and 14.9 AA mg/g). Contrary to these 
results, in our study the berry fruits were found to contain low to moderate amounts of polyphenols and have low to moderate antioxidant activities, with significant variations from each other.

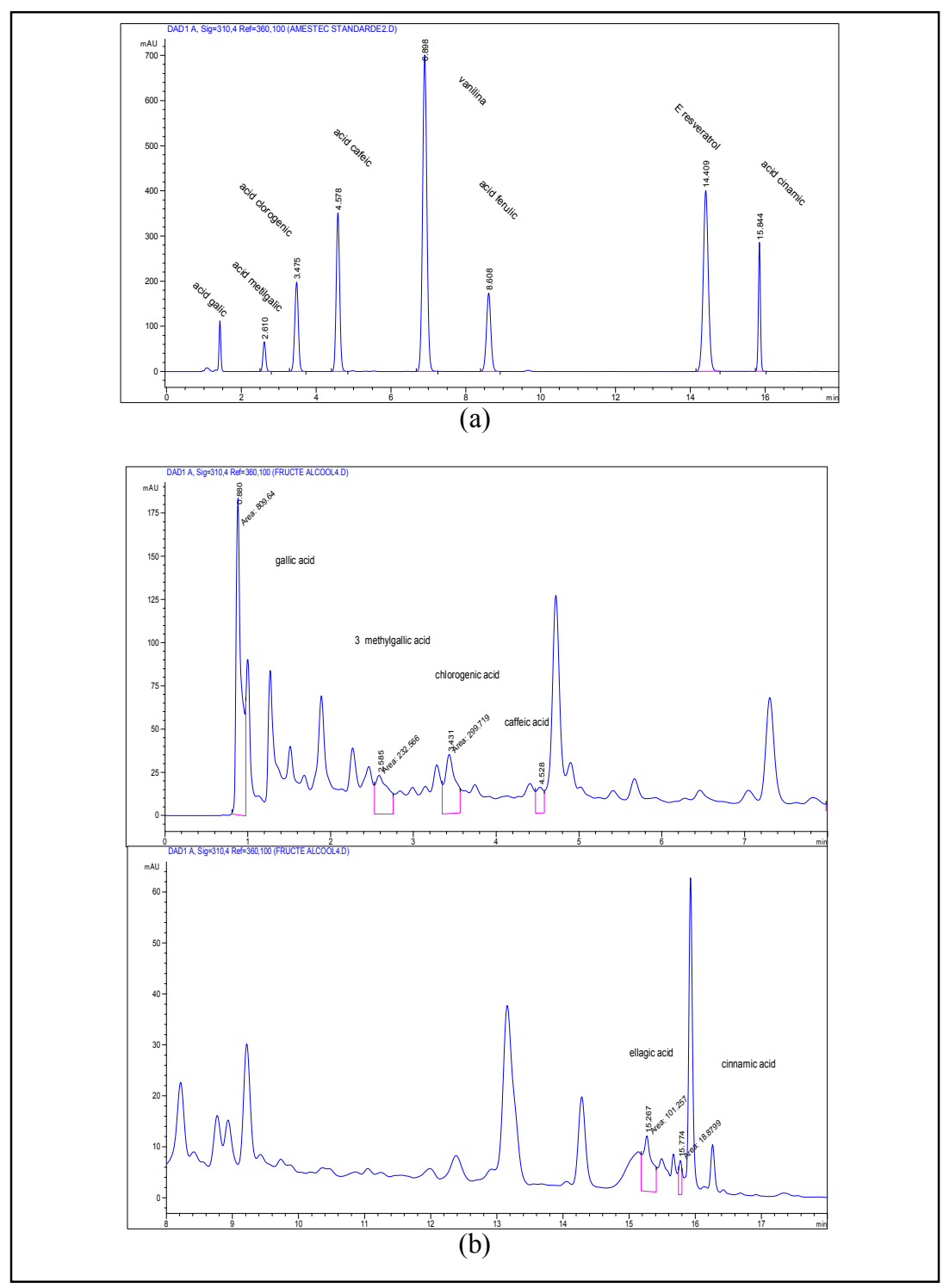

Figure 1. Typical HPLC-DAD chromatograms: (a) standard polyphenols and (b) phenolic compounds in Vaccinium vitis-idaea infusions. 
It is known that the antioxidant activity of fruits is influenced by their phenolic composition [27]. In order to evaluate the contribution of phenolic compounds to the antioxidant activity of berry infusions, correlation coefficient was calculated. These was a strong, positive and significant correlation $(r=0.9465)$ between the FRAP values and TP content meaning the concentration of phenolic compounds may be a good indicator of the reducing capacity in the infusions. Instead a lower, positive and not significant correlation was found between FRAP and ACN $(r=0.209)$. These results could indicate that other compounds, such as vitamin, unquantified phenolics, could be contributing to the antioxidant capacity of these infusions [28, 29]. The highest reducing capacity was found in rose hip (BT1) infusion $\left(19.45 \mathrm{mM} \mathrm{FeSO}_{4} / \mathrm{L}\right)$ and the lowest in BT2 $\left(2.31 \mathrm{mM} \mathrm{FeSO}_{4} / \mathrm{L}\right)$. The average reducing capacity of the seven studied berry fruit infusions was $6.99 \mathrm{mM} \mathrm{FeSO}_{4} / \mathrm{L}$. As in other several studies [30-33], we found a quite good correlation between antioxidant activities measured by FRAP assay and the total polyphenolic content of the samples, which indicate that the polyphenols considerably contribute to total antioxidant capacity.

Significant positive correlation $(\mathrm{p}<0.05)$ was found between the results of antioxidant assays (FRAP) and gallic acid (Pearson correlation, $\mathrm{r}=0.563$ ). The correlation coefficients between the other phenolic compounds and antioxidant activity were weak. Our results indicated that this compound contributed particularly to the total antioxidant capacity of the studied samples. This can be attributed to the structure of gallic acid characterized by the presence of several hydroxy groups, which exhibit a greater ability to donate a hydrogen atom and to support the unpaired electron.

\section{Total and extractable microelements}

It is well-known fact that plant species commonly used to prepare popular beverages (tisane, herbal tea) contain certain micro-elements and macro-elements, having as main source the soil and its profile. Therefore, their microelements concentrations in these beverages may vary with the fruit species, its preferential absorbability of the element, mineral composition of the soil in which the plant was grown and the climatic conditions [34]. On the other hand, the technology of the beverage processing, as well as the $\mathrm{pH}$ value of the extraction phase can influence the concentration of metals in the final product [35].

All the microelements which were measured in our study are of major importance for human health $[36,37]$. The results presented in Table 5 showed significant varietal $(p<0.05)$ differences in microelement content and extractability. The concentration of iron in dried fruits ranged from $3.97 \mathrm{mg} / 100 \mathrm{~g}$ in BT1 to $104.50 \mathrm{mg} / 100 \mathrm{~g}$ in BT4. Compared with the fresh berry fruits, the teas had higher content of iron, including strawberries $(12.15 \mu \mathrm{g} / \mathrm{g})$ and lingonberries $(17 \mu \mathrm{g} / \mathrm{g})$ [38]. Despite the higher amount of Fe found in berry fruit teas in this study, the bioavailability of this element is very low. Only $0.30-6.79 \%$ of the total iron of berry teas studied was available for absorption. This could be attributed to the fact that the presence of polyphenols is usually associated with low extractability of minerals [39].

The copper content in dried fruits ranged from $0.84 \mathrm{mg} / 100 \mathrm{~g}$ in the BT3 sample to 2.38 $\mathrm{mg} / 100 \mathrm{~g}$ in mixture sample (BT5). The extractability study indicated that only $1.38-38 \%$ from the total copper is available for absorption. Copper content of infusions varies significantly $(\mathrm{p}<$ 0.05), BT5 showing the highest percentage of extractability and BT1 the lowest one.

The zinc content of the dried fruits varied from $2.52 \mathrm{mg} / 100 \mathrm{~g}$ in BT1 to $14.34 \mathrm{mg} / 100 \mathrm{~g}$ in BT4 sample. On the other hand, Zn extractability of infusions varied significantly $(p<0.05)$ and ranged between $3.84 \%$ and $38.61 \%$. Although BT3 had the lowest Zn content it showed the highest extractability. In contrast, the mixtures which had the highest $\mathrm{Zn}$ values, showed lowest extractability. This low extractability could be due to the presence of antinutritional factors such as polyphenols and flavonoids in berry infusions. 
Manganese content of berry fruit teas ranged between $3.60 \mathrm{mg} / 100 \mathrm{~g}$ and $83.98 \mathrm{mg} / 100 \mathrm{~g}$, the highest Mn content was found in BT4, whereas the lowest content was observed in BT4 sample. Manganese extractability in berry tea varieties were significantly different $(\mathrm{p}<0.05)$ and were within the range of $6.67-47.83 \%$, the Hibiscus sabdariffa infusion, having the highest level of Mn.

Regarding the extractability of microelements in berries fruit teas, according to their average extraction percentage, they can be ranged in the following order: $\mathrm{Mn}>\mathrm{Zn}>\mathrm{Cu}>\mathrm{Fe}$. Generally, with the exception of $\mathrm{Mn}$, which present a moderate extractability, lower extractability was observed in the majority of microelements [40].

Table 5. Total (mg/100 g) and extractability (\%) of microelements of different berry fruit teas.

\begin{tabular}{|l|c|c|c|c|c|c|c|c|}
\hline \multirow{2}{*}{ Tea } & \multicolumn{2}{|c|}{$\mathrm{Mn}$} & \multicolumn{2}{c|}{$\mathrm{Fe}$} & \multicolumn{2}{c|}{$\mathrm{Cu}$} & \multicolumn{2}{c|}{$\mathrm{Zn}$} \\
\cline { 2 - 9 } & $\mathrm{mg} / 100 \mathrm{~g}$ & $\%$ & $\mathrm{mg} / 100 \mathrm{~g}$ & $\%$ & $\mathrm{mg} / 100 \mathrm{~g}$ & $\%$ & $\mathrm{mg} / 100 \mathrm{~g}$ & $\%$ \\
\hline BT1 & $34.64 \pm 2.39$ & $12.28 \pm 0.42$ & $3.97 \pm 0.76$ & $0.30 \pm 0.08$ & $1.73 \pm 0.04$ & $1.38 \pm 0.41$ & $2.52 \pm 0.07$ & $3.84 \pm 0.22$ \\
\hline BT2 & $37.09 \pm 2.02$ & $30.49 \pm 3.60$ & $19.92 \pm 0.71$ & $2.09 \pm 0.26$ & $2.04 \pm 0.05$ & $1.44 \pm 0.17$ & $3.69 \pm 0.08$ & $24.10 \pm 1.05$ \\
\hline BT3 $3.60 \pm 0.16$ & $6.67 \pm 0.22$ & $20.10 \pm 0.40$ & $1.57 \pm 0.15$ & $0.84 \pm 0.06$ & $4.82 \pm 0.22$ & $3.26 \pm 0.07$ & $38.61 \pm 2.13$ \\
\hline BT4 & $83.98 \pm 3.28$ & $47.83 \pm 2.09$ & $104.50 \pm 1.78$ & $6.79 \pm 0.35$ & $1.29 \pm 0.04$ & $4.70 \pm 0.21$ & $14.34 \pm 0.23$ & $13.25 \pm 1.21$ \\
\hline BT5 $63.08 \pm 1.80$ & $31.90 \pm 1.45$ & $59.38 \pm 1.22$ & $0.56 \pm 0.11$ & $2.38 \pm 0.02$ & $38.0 \pm 1.73$ & $8.98 \pm 0.33$ & $10.85 \pm 0.67$ \\
\hline BT6 $61.29 \pm 2.08$ & $28.54 \pm 1.16$ & $74.66 \pm 1.25$ & $0.92 \pm 0.14$ & $2.05 \pm 0.13$ & $1.70 \pm 2.10$ & $9.66 \pm 0.19$ & $0.83 \pm 0.75$ \\
\hline BT7 $60.31 \pm 2.56$ & $28,35 \pm 0.52$ & $69.27 \pm 0.51$ & $0.42 \pm 0.11$ & $2.17 \pm 0.11$ & $1.941 \pm 1.55$ & $9.38 \pm 0.16$ & $0.89 \pm 0.63$ \\
\hline
\end{tabular}

\section{The correlation between antioxidant capacity and mineral extractability}

Table 6 present the correlation between total polyphenols, total anthocyanin contents, antioxidant capacity and the determined microelements in berry fruit infusions. Our results show that there were many correlations (positive, negative, weak) between antioxidant capacity and mineral extractability. Generally, positive correlations were observed between total polyphenols and $\mathrm{Fe}, \mathrm{Mn}, \mathrm{Cu}$ and $\mathrm{Zn}$ content in our research. Thus, total polyphenols content showed moderate correlation with $\mathrm{Cu}(\mathrm{r}=0.439)$, weak correlations with $\mathrm{Mn}(\mathrm{r}=0.352)$ and $\mathrm{Zn}(\mathrm{r}=$ $0.375)$ and very weak correlation with $\mathrm{Fe}(\mathrm{r}=0.186)$. These results demonstrate that total polyphenols in berry infusions has a significant impact on enhancing the extractability of $\mathrm{Cu}$ and Mn bound with the ability to form chelated metal ions by polyphenol compounds and to retain them but $\mathrm{Zn}$ has smaller effect on the extractability of iron. In addition, these results are more effectively complex into the macromolecular structures by condensed flavonoids, reported for extracts of medicinal plants [41].

Table 6. Correlation coefficient of antioxidant activity and mineral extractability of berry fruit infusions.

\begin{tabular}{|l|c|c|c|c|}
\hline Person correlation & $\mathrm{Fe}$ & $\mathrm{Mn}$ & $\mathrm{Cu}$ & $\mathrm{Zn}$ \\
\hline Total polyphenol content & $0.186(\mathrm{p}>0.05)$ & $0.352(\mathrm{p}>0.05)$ & $0.439(\mathrm{p}<0.05)$ & $0.373(\mathrm{p}>0.05)$ \\
\hline Ferric reducing power (FRAP) & $0.189(\mathrm{p}>0.05)$ & $-0.273(\mathrm{p}>0.05)$ & $-0.410(\mathrm{p}<0.05)$ & $-0.274(\mathrm{p}>0.05)$ \\
\hline Total anthocyanins (ACN) & $0.201(\mathrm{p}>0.05)$ & $0.632(\mathrm{p}<0.05)$ & $-0.034(\mathrm{p}>0.05)$ & $0.635(\mathrm{p}<0.05)$ \\
\hline
\end{tabular}

Correlation is significant at $\mathrm{p}<0.05$.

Additionally, the FRAP was negatively correlated with $\mathrm{Cu}(\mathrm{r}=-0.410), \mathrm{Mn}(\mathrm{r}=-0.273)$ and $\mathrm{Zn}(\mathrm{r}=-0.274)$ and very weak correlated with $\mathrm{Fe}(\mathrm{r}=0.189)$. Regarding anthocyanins, we obtained positive and significant $(\mathrm{p}<0.05)$ correlation between anthocyanins and $\mathrm{Mn}$ and $\mathrm{Zn}(\mathrm{r}$ $=0.632$ and $r=0.635$, respectively), but weak correlation with $\mathrm{Fe}(\mathrm{r}=0.201)$. This is the first study on the correlation between antioxidant capacity and some microelement extractability on berries fruit infusions. The previous studies describe the correlation between polyphenols and antioxidant with mineral content in fruits or vegetables, but do not describe the correlation with mineral extractability $[42,43]$. 


\section{CONCLUSION}

The analyzed infusions, prepared according to the indications of the berry fruit teas producers, have a poor to medium polyphenols, anthocyanins and mineral elements content. There is a high, positive and significant correlation $(r=0.9465)$ between the FRAP values and TP content, meaning that the concentration of phenolic compounds may be a good indicator of the reducing capacity in the infusions. The significant antioxidant activities could recommend the infusions obtained from berry fruit teas as dietary supplements in winter time.

\section{ACKNOWLEDGEMENT}

This work was supported by the Department of Pharmaceutical Sciences, University of Constantza.

\section{REFERENCES}

1. Folmer, F.; Basavaraju, U.; Jaspars, M.; Hold, G.; Omar-El, E.; Mario Dicato M.; MarcDiederich, D. Anticancer effects of bioactive berry compounds. Phytochem. Rev. 2014, 13, 295-322.

2. Paredes-López, O.; Cervantes-Ceja, M.L.; Vigna-Pérez. M.; Hernández-Pérez, T. Berries: Improving human health and healthy aging, and promoting quality life: A review. Plant Foods Human Nutr. 2010, 65, 299-308.

3. Zorenc, Z.; Veberic, R.; Stampar, F.; Koron, D.; Mikulic-Petkovsek, M. Changes in berry quality of northern highbush blueberry (Vaccinium corymbosum L.) during the harvest season. Turk. J. Agric. For. 2016, 40, 855-867.

4. Rop, O.; Ercisli, S.; Mlcek, J.; Jurikova, T.; Hoza, I. Antioxidant and radical scavenging activities in fruits of 6 sea buckthorn (Hippophae rhamnoides L.) cultivars. Turk. J. Agric. For. 2014, 38, 224-232.

5. Veberic, R.; Slatnar, A.; Bizjak, J.; Stampar, F.; Petkovsek-Mikulic, M. Anthocyanin composition of different wild and cultivated berry species. Food Sci. Technol. 2015, 60, 509-517.

6. Gundogdu, M.; Kan, T.; Canan, I. Bioactive and antioxidant characteristics of blackberry cultivars from East Anatolia. Turk. J. Agric. For. 2016, 40, 344-351.

7. Eichhorn, T.; Greten, H.J.; Thomas-Efferth, T. Self-medication with nutritional supplements and herbal over-the counter products. Nat. Prod. Bioprospect. 2011, 1, 62-70.

8. Michalczyk, M.; Macura, R.; Matuszak. I. The effect of air-drying, freeze-drying and storage on the quality and antioxidant activity of some selected berries. J. Food Process. Preserv. 2009, 33, 11-21.

9. Savikin, K.; Zdunic, G.; Jankovic, T.; Godevac, D.; Stanojkovic, T.; Pljevliakusic, D. Berry fruit teas: Phenolic composition and cytotoxic activity. Food Res. Int. 2014, 62, 677-683

10. García-Rico, L.; Leyva-Perez, J.; Martin, E.; Jara-Marini, M.E. Content and daily intake of copper, zinc, lead, cadmium, and mercury from dietary supplements in Mexico. Food Chem. Toxicol. 2007, 45, 1599-1605.

11. Jeszka-Skowwron, M.; Krawczyk, M.; Zgola-Grzeskowiak, A. Determination of antioxidant activity, rutin, quercetin, phenolic acids and trace elements in tea infusions: Influence of citric acid addition on extraction of metals. J. Food Compos. Anal. 2015, 40, 70-77.

12. Giusti, M.M.; Wrolstod, R.E. Characterization and Measurement of Anthocyanins by UVVisible Spectroscopy in Handbook of Food Analytical Chemistry, John Wily and Sons: New Jersey; 2001; pp 19-31. 
13. Singleton,V.L.; Oethofer, R.; Lamela-Raventos, R.M. Analysis of total phenols and other oxidation substrates and antioxidants by means of folin-ciocalteu reagent. Methods Enzymol. 1999, 299, 152-178.

14. United States Pharmacopeia and National Formulary (USP 30-NF 25), Rockville, MD: United States Pharmacopeia Convention 2007, 28, 914-918.

15. Benzie, I.F.; Szeto, Y.T. Total antioxidant capacity of tea by ferric reducing antioxidant power assay. J. Agric. Food Chem. 1999, 47, 630-636.

16. AOAC Official methods of analysis of the Association of Official Analytical Chemists $(A O A C)$ 15th ed., AOAC, International: Arlington, Virginia, USA; 1990; 1298.

17. Ogunkunle, A.T.J.; Bello, O.S.; Ojofeitimi, O.S. Determination of heavy metal contamination of street-vended fruits and vegetables in Lagos state, Nigeria. Int. Food Res. J. 2014, 21, 1725-1730.

18. Bowen-Forbes, C.S.; Zhang, Y.; Nair, M.G. Anthocyanin content, antioxidant, antiinflammatory and anticancer properties of blackberry and raspberry fruits. J. Food Compos. Anal. 2010, 23, 554-560.

19. Teleszko, M.; Nowicka, P.; Wojdylo, A. Effect of cultivar and storage temperature on identification and stability of polyphenols in strawberry cloudy juices. J. Food Compos. Anal. 2016, 54, 10-19.

20. Belscak, A; Bukovaci, N.; Piljac-Zegarac, J. The influence of ascorbic acid and honey addition on the antioxidant properties of fruit tea infusions; antioxidants in fruit tea infusions. J. Food Biochem. 2011, 35, 195-212.

21. Salah, A.M.; Gathumbi, J.; Vierling, W. Inhibition of intestinal motility by methanol extracts of Hibiscus sabdariffa L. (Malvaceae) in rats. Phytother. Res. 2002, 16, 283-285.

22. Rodríguez-Medina, I.C.; Beltrán-Debón, R.; Micol Molina, V.; Alonso-Villaverde, C. Joven, J.; Menéndez, J.A.; Segura-Carretero, A.; Fernández-Gutiérrez, A. Direct characterization of aqueous extract of Hibiscus sabdariffa using HPLC with diode array detection coupled to ESI and ion trap MS. J. Sep. Sci. 2009, 32, 3441-3448

23. Rösch, D.; Bergmann, M.; Knorr, D.; Kroh.; L.W. Structure-antioxidant efficiency relationships of phenolic compounds and their contribution to the antioxidant activity of sea buckthorn juice. J. Agric. Food Chem. 2003, 51, 4233-4239.

24. Tumbas, Vesna T.; Čanadanović-Brunet, J.M.; Četojević-Simin, D.D.; Ćetković, G.S.; Đilas, S.M.; Gille, L. Effect of rosehip (Rosa canina L.) phytochemicals on stable free radicals and human cancer cells. J. Sci. Food Agric. 2012, 92, 1273-1281.

25. Pulido, R.; Bravo, L.; Saura-Calixto, F. Antioxidant activity of dietary polyphenols as determined by a modified ferric reducing/antioxidant power assay. J. Agric. Food Chem. 2000, 48, 3396-3402.

26. Buricova, L.; Reblova, Z. Czech medicinal plants as possible sources of antioxidants. Czech J. Food Sci. 2007, 26, 132-138.

27. Imeh, U.; Khokhar, S. Distribution of conjugated and free phenols in fruits: Antioxidant activity and cultivar variations. J. Agric. Food Chem. 2000, 50, 6301-6306.

28. Canan, I.; Gundogdu, M.; Seday U.; Oluk, C.A.; Karasahin, Z.; Eroglu, E.C.; Yazici, E.; Unlu, M. Determination of antioxidant, total phenolic, total carotenoid, lycopene, ascorbic acid, and sugar contents of citrus species and mandarin hybrids. Turk. J. Agric. For. 2016, 40, 894-899.

29. Hegedus, A.; Engel, R.; Abrankó, L.; Balogh, E.; Blázovics, A.; Hermán, R.; Halasz, J.; Ercisli, S.; Pedryc, A.; Stefanovits-Bányai, É. Antioxidant and antiradical capacities in apricot (Prunus armeniaca L.) fruits: Variations from genotypes, years, and analytical methods. J. Food Sci. 2010, 75, C722-730.

30. Pellegrini, N.; Serafini, M.; Colombi, B.; Del Rio, D.; Salvatore, S.; Bianchi, M.; Brighenti, F. Total antioxidant capacity of plant foods, beverages and oils consumed in Italy assessed by three different in vitro assays. J. Nutr. 2003, 133, 2812-2819. 
31. Pantelidis, G.E.; Vasilakakis, M.; Manganaris, G.A.; Diamantidis, G. Antioxidant capacity, phenol, anthocyanin and ascorbic acid contents in raspberries, blackberries, red currants, gooseberries and cornelian cherries. Food Chem. 2007, 102, 777-783.

32. Ercisli, S.; Orhan, E. Some physico-chemical characteristics of black mulberry (Morus nigra L.) genotypes from Northeast Anatolia region of Turkey. Sci. Hortic. 2008, 116, 41-46.

33. Thaipong, K.; Boonprakob, U.; Crosby, K.; Cisneros-Zevallos, L.; Hawkins, B.D. Comparison of ABTS, DPPH, FRAP, and ORAC assays for estimating antioxidant activity from guava fruit extracts. J. Food Compos. Anal. 2006, 19, 669-675.

34. Szymczycha-Madeja, A.; Walma, M.; Pohl, P. Elemental analysis of teas and their infusions by spectrometric methods. Trends Anal. Chem. 2012, 35, 165-181

35. Karak, T.; Bhagat, R.M. Trace elements in tea leaves, made tea, and tea infusion: A review. Food Res. Int. 2010, 43, 2234-2252.

36. World Health Organization (WHO) Evaluation of Certain Food Additives and Contaminants in WHO Technical Report Series 930, WHO: Geneva, Switzerland; 2006.

37. Vicente, A.R.; Manganaris, G.A.; Ortiz, C.M.; Sozzi, G.O.; Crisosto, C.H. Nutritional Quality of Fruit and Vegetables, 2nd ed., Academic Press: Oxford; 2014; chapter 5, pp 57106 ,

38. Ekholm, P.; Reinivuo, H.; Mattila, P.; Pakkala, H.; Koponen, J.; Happonen, A.; Hellström, J.; Ovaskainen, M.L. Changes in the mineral and trace element contents of cereals, fruits and vegetables in Finland. J. Food Compos. Anal. 2007, 20, 487-495.

39. Peralta, R.M. Phenolic compounds in fruits - An overview. Int. J. Food Sci. Technol. 2012, 47, 2023-2044.

40. Natesan, S.; Ranganathan, V. Content of various elements in different part of tea plant and in infusion of black tea from South India. J. Agric. Food Chem. 1990, 51, 125-139.

41. Whittaker, A.; Vazzana, C.; Vecchio, V.; Benedettelli, S. Evaluation of direct and indirect effects of flavonoids, mineral elements and dry weight on antiradical scavenging activity in leaf material of field-grown Trifolium pretense cultivars using path analysis. Field Crops Res. 2009, 113, 1-11.

42. Mohamed-Rania, M.A.; Fageer-Aisha, S.M.; Mohamed, M.; Eltayeb-Mohamed Ahmed Isam, A. Chemical composition, antioxidant capacity, and mineral extractability of Sudanese date palm (Phoenix dactylifera L.) fruits. Food Sci. Nutr. 2014, 2, 478- 489.

43. Sulaiman, S.F.; Yusoff, N.A.M.; Eldeen, I.M.; Seow, E.M.; Sajak-Supriatno, A.B.; Ooi, K.L. Correlation between total phenolic and mineral contents with antioxidant activity of eight Malaysian bananas (Musa sp.). J. Food Compos. Anal. 2011, 24, 1-10. 